Check for updates

Cite this: RSC Adv., 2017, 7, 39556

Received 17th July 2017

Accepted 7th August 2017

DOI: $10.1039 / \mathrm{c} 7 \mathrm{ra07851j}$

rsc.li/rsc-advances

\section{Extraction kinetics of mixed rare earth elements with bifunctional ionic liquid using a constant interfacial area cell $\uparrow$}

\author{
Yanliang Wang, ${ }^{\text {ab }}$ Yabing Wang, ${ }^{\text {ac }}$ Haiyue Zhou, ${ }^{a}$ Fujian Lid ${ }^{\text {ad }}$ and Xiaoqi Sun (DD *ab
}

As a bifunctional ionic liquid used for the extraction of yttrium and heavy rare earth elements (REEs), [methyltrioctyl ammonium][(2,6-dimethylheptyl) phenoxy acetic acid] ([ $\left.\left.\mathrm{N}_{1888}\right][\mathrm{POAA}]\right)$ has been synthesized in this paper. The extraction kinetics of REEs including La-Lu plus Y except Pm with $\left[\mathrm{N}_{1888}\right]$ [POAA] using a constant interfacial area cell were reported. Comparing with the conventional (2,6-dimethylheptyl) phenoxy acetic acid (HPOAA) extraction system, the forward extraction rate $\left(k_{\mathrm{ao}}, \mathrm{mm} \mathrm{s}^{-1}\right)$ of heavy REEs in the $\left[\mathrm{N}_{1888}\right]$ [POAA] extraction system increased significantly with an improvement of 8.44 times for yttrium. The effect of stirring speed on the extraction rate of mixed REEs was studied and $300 \mathrm{rpm}$ was suggested to ensure the extraction regimes were chemical reactioncontrolled. The effect of temperature was studied and the extraction reaction was controlled by chemical reaction when the temperature was below $298 \mathrm{~K}$. The effect of specific interfacial area was also evaluated which indicated that the bulk phase was the reaction zone. The average extraction rate equation of REEs has also been obtained as: $-d[R E]_{(0)} / d t=0.141\left[R C_{3}\right]\left(\left[N_{1888}\right][P O A A]\right)$.

\section{Introduction}

Rare earth elements (REEs), including La-Lu, Sc and Y, have become critical materials in various fields, such as in catalysts, alloys, magnets, lasers, batteries, electronics, lighting, and telecommunications. ${ }^{1}$ Heavy REEs consisting of Y, Gd, Tb, Dy, $\mathrm{Ho}, \mathrm{Er}, \mathrm{Tm}, \mathrm{Yb}$ and $\mathrm{Lu}$ exhibit irreplaceable specific performance, therefore, they have become important elements in exploring high technology materials. ${ }^{2}$ Solvent extraction processes have been well established and widely applied in the REEs separation industry of China with organic phosphonic/ phosphoric acids and carboxylic acids. ${ }^{3,4}$ However, the saponification of the acidic extractants results in the release of $\mathrm{NH}_{4}{ }^{+}$, $\mathrm{Na}^{+}, \mathrm{Ca}^{2+}$ or $\mathrm{Mg}^{2+}$ to wastewaters and serious pollution. There is a growing interest in developing new extractants and corresponding materials to solve these problems. ${ }^{5}$

Ionic liquids are a series of organic salts which have received much attention as green solvents in many fields. ${ }^{6,7}$ Bifunctional ionic liquids (BILs) composed of quaternary ammonium/

${ }^{a}$ Xiamen Institute of Rare Earth Materials, Haixi Institute, Chinese Academy of Sciences, Xiamen 361021, China. E-mail: xqsun@fjirsm.ac.cn; Fax: +86 5926376370; Tel: +865926376370

${ }^{b}$ Fujian Institute of Research on the Structure of Matter, Chinese Academy of Sciences, Fuzhou, Fujian 35002, China

'Jiangxi University Science \& Technology, School of Metallurgy \& Chemical Engineering, Ganzhou 341000, China

${ }^{d}$ Ganzhou Rare Earth Group Co., Ltd., Ganzhou 341000, China

$\dagger$ Electronic supplementary information (ESI) available. See DOI: 10.1039/c7ra07851j phosphonium cation and monobasic acidic extractant, have become the focus of research for the separation of yttrium and heavy REEs in recent years. ${ }^{8}$ The inner synergistic effects of BILs for solvent extraction of metal ions using [tricaprylmethyl ammonium][di-2-ethylhexyl phosphinate] as extractant have been reported. ${ }^{9-11}$ The results show that the extraction efficiency of REEs has been enhanced and the selectivity has been changed in the BIL system. Other advantages, such as avoiding saponification wastewater from the application of acidic extractants, low acidity for extraction and good interfacial phenomena, have emerged. ${ }^{12,13}$ (2,6-Dimethylheptyl) phenoxy acetic acid (HPOAA) and [methyltrioctyl ammonium $\left(\mathrm{N}_{1888}\right)$ ] [POAA] have been synthesized in this lab recently. The former was used for the separation of high-purity yttrium from ionabsorbed rare earth ore. ${ }^{\mathbf{1 4}-16}$ The later was used for the development of sustainable yttrium separation process from heavy rare earth enrichments. ${ }^{17}$ Equilibrium data have been collected and the separation process for industrial application may contribute to eliminating the saponification process and avoiding the acid or base consumption. However, there still remains considerable uncertainty about the kinetics involved in the extraction of REEs, such as extraction regimes (diffusion, chemical reaction or mixed controlled) and chemical reaction zone which control the rate of extraction in the bulk phases or at the liquid-liquid interface.

Although there were various instruments and methods to determine how the extraction rates depended on the time, such as single drop technique, ${ }^{\mathbf{1 8}, 19}$ hollow fiber membrane method, ${ }^{20,21}$ centrifugal partition chromatography, ${ }^{22}$ constant 
Table 1 The kinetic mechanism including extraction regime and reaction zone of metal ions with extractants using constant interfacial area cell

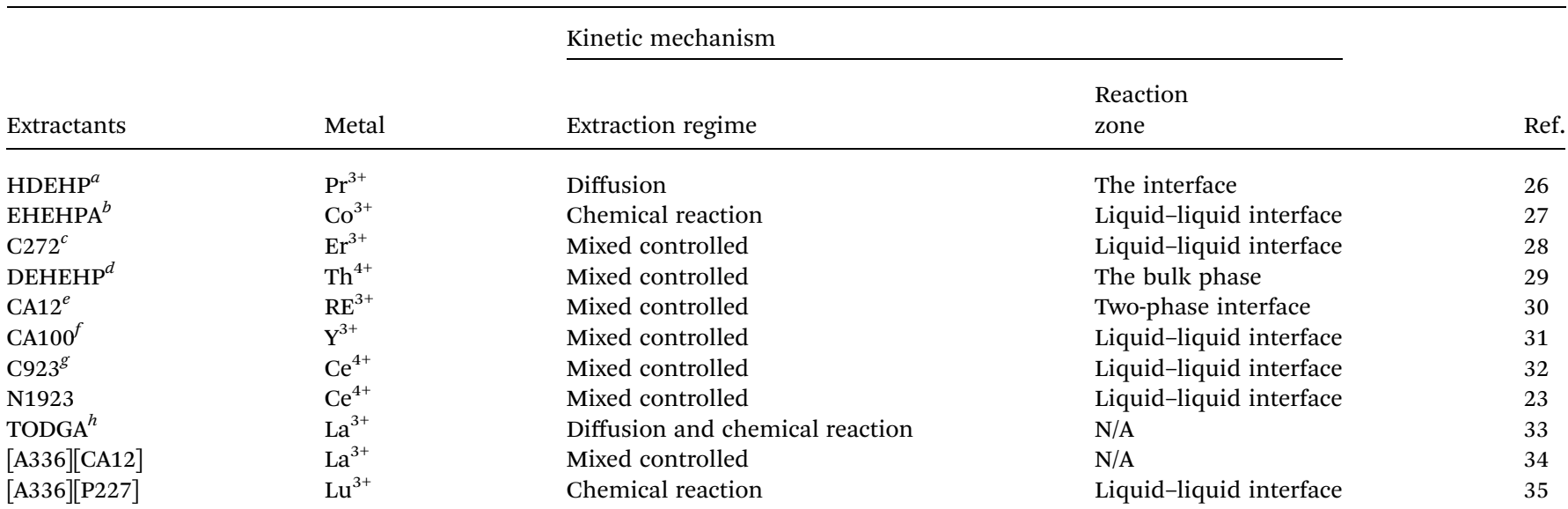

${ }^{a}$ HDEHP is di(2-ethylhexyl)phosphoric acid. ${ }^{b}$ EHEHPA is (2-ethylhexyl)phosphoric acid mono-ethylhexyl ester. ${ }^{c}$ C272 is Cyanex 272, bis(2,4,4trimethylpentyl)phosphinic acid. ${ }^{d}$ DEHEHP is di-(2-ethylhexyl)-2-ethylhexyl phosphonate. ${ }^{e}$ CA12 is sec-octylphenoxy acetic acid. ${ }^{f}$ CA100 is secnonylphenoxy acetic acid. ${ }^{g} \mathrm{C} 923$ is Cyanex $923\left(\mathrm{R}_{3} \mathrm{P}=\mathrm{O}\right)$, a mixture of four trialkylphosphine oxides in which each $\mathrm{R}$ group is either hexyl or octyl. ${ }^{h}$ TODGA is $N, N, N^{\prime}, N^{\prime}$-tetraoctyl diglycolamide.

interfacial area cell ${ }^{23,24}$ and microfluidic method, ${ }^{25}$ the cell among which was used wildly for its stability and reproducibility data. Literature related to this research was shown in Table 1. The main problem of these conventional extraction systems was that, the interfacial transfer limited by diffusion of molecules to the interface at the relatively slow mixing and small specific interfacial areas $\left(1-100 \mathrm{~m}^{2} \mathrm{~m}^{-3}\right.$ ) rather than chemical reaction, and reaction zone which controlled the rate of extraction usually at the liquid-liquid interface.

Task-specific ionic liquids [tricaprylmethylammonium][secoctylphenoxy acetic acid] ([A336][CA12]) and [tricaprylmethyl ammonium][di-(2-ethylhexyl) phosphinic acid] ([A336][P227]) were synthesized and the extraction kinetics of $\mathrm{La}^{3+}$ and $\mathrm{Lu}^{3+}$ from aqueous chloride solutions into $n$-heptane solutions were discussed, respectively. ${ }^{34,35}$ However, less reports to our knowledge concern the extraction kinetics of mixed rare earth elements using a constant interfacial area cell. The main idea of this paper is to elaborate the extraction rates of 15 kinds of REEs from aqueous solution into bifunctional ionic liquid $\left[\mathrm{N}_{1888}\right]$ [POAA] which closer to the industrial conditions. The effects of stirring speed, temperature, specific interfacial area and extractant concentration on the extraction rate were examined. The kinetic mechanism concerns whether the extraction process was controlled by diffusion or chemical reaction, and whether the reaction zone was in the bulk phases or at the interface were involved.

\section{Experimental}

\subsection{Materials and methods}

Methyltrioctyl ammonium chloride ( $\left[\mathrm{N}_{1888}\right] \mathrm{Cl}$, purity $\left.>99 \%\right)$ was purchased from Anhui Benma Pioneer Technology Co., Ltd., China. (2,6-Dimethylheptyl) phenol and sodium chloroacetate were purchased from Chendu Xiya Reagent Chemical Technology Co., Ltd. Individual REE stock solutions, including La-Lu plus $\mathrm{Y}$, were prepared by dissolving the corresponding oxide (>99.99\%, Ganzhou Rare Earth Group Co., Ltd., China) with hydrochloric acid and diluting with deionized water. All the chemicals were used without further purification.

Inductively coupled plasma optical emission spectroscopy (ICP-OES) Horiba Ultima 2 was used to determine the concentrations of REEs. ${ }^{1} \mathrm{H}$ and ${ }^{13} \mathrm{C}$ nuclear magnetic resonance (NMR) spectra were obtained in $\mathrm{CDCl}_{3}$ with an AV III-500 BRUKER spectrometer.

The molecular structure of (2,6-dimethylheptyl) phenoxy acetic acid (HPOAA) and $\left[\mathrm{N}_{1888}\right][\mathrm{POAA}]$ are shown in Fig. 1 . The former was prepared in laboratory scale via Williamson reaction and the synthetic routes were described. ${ }^{16}$ The later was prepared by acid-base neutralization method. ${ }^{17}$ The amount of residual $\mathrm{Cl}^{-}$in the product of $\left[\mathrm{N}_{1888}\right][\mathrm{POAA}]$ determined was lower than $0.07 \mathrm{wt} \%$.

\subsection{Experimental procedures}

A constant interfacial area cell which improved from Nitschtype stirred cell $^{36}$ was adopted to investigate the extraction kinetics. As shown in Fig. 2(a), the cell whose phase was independently agitated with a stirring paddle was made of

(a)<smiles>[R]CC(C)CCCC(C)C</smiles>

(b)

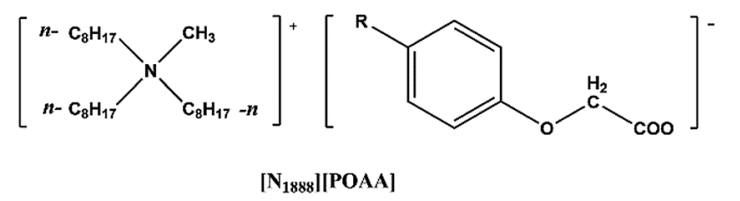

Fig. 1 The molecular structures of HPOAA (a) and $\left[\mathrm{N}_{1888}\right][\mathrm{POAA}](\mathrm{b})$. 

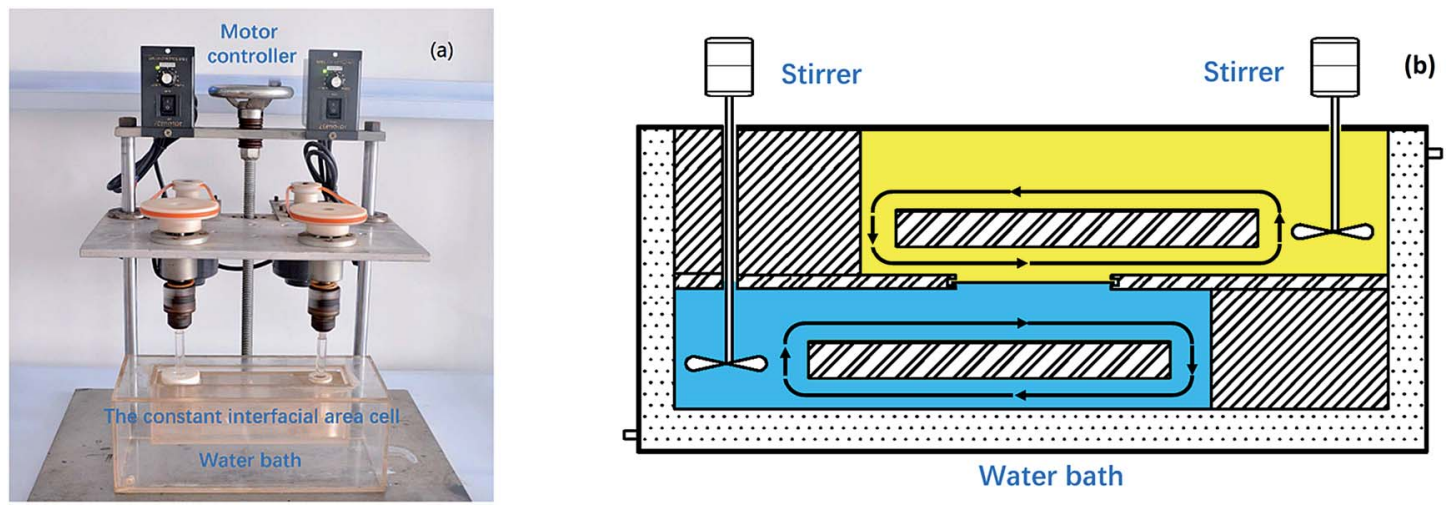

Fig. 2 The experimental equipment of kinetics (a) and detailed structure of the constant interfacial area cell (b) used to study the extraction kinetics.

transparent polymethyl methacrylate. Under the combined action of stirring paddles and flow deflectors, the lighter phase and the heavier phase circulate in each chamber and move near the interface in lamina, respectively (Fig. 2(b)). The interfacial plate was a rectangle plate with a hole of $8-28 \mathrm{~cm}^{2}$. Temperature was controlled with a circulating water bath at constant temperature $(298 \mathrm{~K})$ except for temperature experiments. Equal volumes of $90 \mathrm{~mL}$ each of aqueous and organic phases were individually added to the cell chamber using a syringe. After stirring was started, $0.2 \mathrm{~mL}$ of sample was collected at $10 \mathrm{~min}$ intervals from the aqueous phase to monitor the extraction of REEs with $\left[\mathrm{N}_{1888}\right][$ POAA] during the kinetic process. The experiments were carried out at a constant stirring rate of $300 \mathrm{rpm}$ except for stirring rate experiments.

\subsection{Data treatment}

This paper discussed the extraction of the mixed rare earth ions with bifunctional ionic liquid and time was the new parameter introduced into the kinetic processes which differ from equilibrium thermodynamics. Because the extraction reactions occurred simultaneously, the extraction model can be formulated as parallel reactions.

$$
[\mathrm{RE}]_{(\mathrm{a})} \underset{k_{\mathrm{oa}}}{\stackrel{k_{\mathrm{ao}}}{\rightleftarrows}}[\mathrm{RE}]_{(\mathrm{o})}
$$

where (a), (o), $k_{\text {ao }}\left(\mathrm{cm} \mathrm{s}^{-1}\right)$ and $k_{\text {oa }}\left(\mathrm{cm} \mathrm{s}^{-1}\right)$ represent the aqueous phase, organic phase, forward extraction rate and backward extraction rate, respectively. RE equals La-Lu plus Y except Pm.

The extraction rate is given by the following equation. ${ }^{37}$

$$
R_{\mathrm{f}}=-\frac{\mathrm{d}[\mathrm{RE}]_{(\mathrm{o})}}{\mathrm{d} t}=-\frac{\mathrm{d} n_{(\mathrm{o})}}{V \mathrm{~d} t}=\frac{A}{V}\left(k_{\mathrm{oa}}[\mathrm{RE}]_{(\mathrm{o})}-k_{\mathrm{ao}}[\mathrm{RE}]_{(\mathrm{a})}\right)
$$

where $n_{(\mathrm{o})}$ is the total number of moles of REEs in the organic phase, $V(\mathrm{~mL})$ is the volume of either aqueous or organic phase, and $A\left(\mathrm{~cm}^{2}\right)$ is the interfacial area.

At equilibrium time, eqn (2) is equal to zero. Thus,

$$
k_{\mathrm{d}}=\frac{[\mathrm{RE}]_{(\mathrm{o})}{ }^{e}}{[\mathrm{RE}]_{(\mathrm{a})}{ }^{e}}=\frac{k_{\mathrm{ao}}}{k_{\mathrm{oa}}}
$$

where $k_{\mathrm{d}}$ refers to the distribution ratio, and $e$ is the concentration at equilibrium. From the mass balance, eqn (2) can be integrated and rewritten as,

$$
\ln \left(1-\frac{[\mathrm{RE}]_{(\mathrm{o})}}{[\mathrm{RE}]_{(\mathrm{o})}^{e}}\right)=-\frac{A}{V}\left(1+k_{\mathrm{d}}\right) k_{\mathrm{oa}} t
$$

$k_{\mathrm{d}}$ was determined by collecting samples from the aqueous phase at equilibrium.

$$
s \underline{\underline{\text { def }}}-\ln \left(1-\frac{[\mathrm{RE}]_{(\mathrm{o})}}{[\mathrm{RE}]_{(\mathrm{o})}{ }^{e}}\right) \frac{V}{A\left(1+k_{\mathrm{d}}\right)}
$$

$k_{\mathrm{oa}}$ and $k_{\mathrm{ao}}$ can be obtained by curve fitting the plots of $s$ versus time $(t)$.

\section{Results and discussion}

\subsection{Characterization of the experimental equipment}

To verify the accuracy of mass transfer of REEs, theoretical calculation and practical kinetic experiments using the constant interfacial area cell were completed. According to mass transfer model, mass transfer per square centimetre, $T_{\mathrm{r}}$, can be expressed as follows, ${ }^{38}$

$$
T_{\mathrm{r}}=\frac{V C_{\mathrm{ini}} k_{\mathrm{d}}}{A\left(1+k_{\mathrm{d}}\right)}\left(1-\exp \left(-\frac{3 A D_{\mathrm{i}} t}{2 V \delta}\right)\right)
$$

where $V$ is the volume of aqueous phase $(\mathrm{mL}), A$ is interfacial area $\left(\mathrm{cm}^{2}\right), C_{\text {ini }}$ is initial concentration of RE ion in aqueous phase ( $\mathrm{mol} \mathrm{L}^{-1}$ ), $k_{\mathrm{d}}$ is distribution ratio, $t$ is time (second).

$k_{\mathrm{d}}$ can be deduced from $T_{\mathrm{r}}$ as the following equation,

$$
k_{\mathrm{d}}=\frac{T_{\mathrm{r}} F}{C_{\mathrm{ini}}-T_{\mathrm{r}} F}
$$

where $F$ is the conversion factor.

As shown in Fig. $3, k_{\mathrm{d}}$ values predicted by theoretical calculations (Fig. 3(a) and (b)) are close to practical kinetic values obtained from kinetic experiments (Fig. 3(c) and (d)) using the constant interfacial area cell. In comparison with the predicted values, the experimental values in the $\left[\mathrm{N}_{1888}\right][\mathrm{POAA}]$ extraction system were closer than that of the HPOAA extraction system as the reaction proceeds. The relative errors of REEs are less than 
$43 \%$ in the HPOAA extraction system and $25 \%$ in the $\left[\mathrm{N}_{1888}\right]$ [POAA] extraction system after 80 minutes, respectively. Further studies on plots of $-\ln \left(1-[\mathrm{RE}]_{(\mathrm{o})} /[\mathrm{RE}]_{(\mathrm{o})}{ }^{e}\right) V / A /\left(1+k_{\mathrm{d}}\right) v s$. time (Fig. 4) are found to lie on straight lines which indicated that the mass transfer process could be treated as a pseudo-first-order reversible reaction.

Next, the extraction rate in the HPOAA and $\left[\mathrm{N}_{1888}\right][\mathrm{POAA}]$ system have been deduced and the results are presented in Table 2. The literature value of the extraction rates with constant interfacial area and rapid mixing using HDEHP as extractant are also listed in Table 2. Although $\left[\mathrm{N}_{1888}\right][\mathrm{POAA}]$ synthesized from HPOAA and $\left[\mathrm{N}_{1888}\right] \mathrm{Cl}$, there were large difference between $\left[\mathrm{N}_{1888}\right][$ POAA] extraction system and HPOAA system. The position of yttrium lies without the lanthanide series in the HPOAA system and the extraction rate order of HPOAA followed the sequence, $\mathrm{Y}<\mathrm{Lu}<\mathrm{Yb}<\mathrm{Tm}<\mathrm{Er}<\mathrm{Ho}<\mathrm{Dy}<$ $\mathrm{Tb}<\mathrm{La}<\mathrm{Gd}<\mathrm{Ce}<\mathrm{Pr}<\mathrm{Eu}<\mathrm{Nd}<\mathrm{Sm}$. When it was developed to the $\left[\mathrm{N}_{1888}\right][\mathrm{POAA}]$, the extraction rate order follows, $\mathrm{La}<\mathrm{Ce}<\mathrm{Pr}$ $<\mathrm{Nd}<\mathrm{Y}<\mathrm{Ho}<\mathrm{Er}<\mathrm{Gd}<\mathrm{Dy}<\mathrm{Tb}<\mathrm{Eu}<\mathrm{Tm}<\mathrm{Sm}<\mathrm{Yb}<\mathrm{Lu}$.
Comparing with HPOAA extraction system, the forward extraction rates $\left(k_{\mathrm{ao}}, \mathrm{mm} \mathrm{s}^{-1}\right)$ of heavy REEs in $\left[\mathrm{N}_{1888}\right][\mathrm{POAA}]$ extraction system increased significantly. It is interesting to note that the extraction rate of yttrium raised 8.44 times to the original extraction system. In other word, the extraction of heavy REEs were quite effective using the current in $\left[\mathrm{N}_{1888}\right]$ [POAA] extraction system. It is reported that when the acidic extractants were prepared as BILs, their extractabilities could be increased. ${ }^{39}$ Thus, the kinetic results were consistent with the thermodynamic reaction data.

\subsection{Dependence of the extraction rate on stirring speed}

It is known that, the mass transfer rate of metal cations in liquid-liquid solvent extraction systems was a function of both the diffusion of the involved species and the kinetics of the chemical reaction in the two liquid phases. Therefore, diffusion-controlled and chemical reaction-controlled regimes were two representative types of extraction regimes.
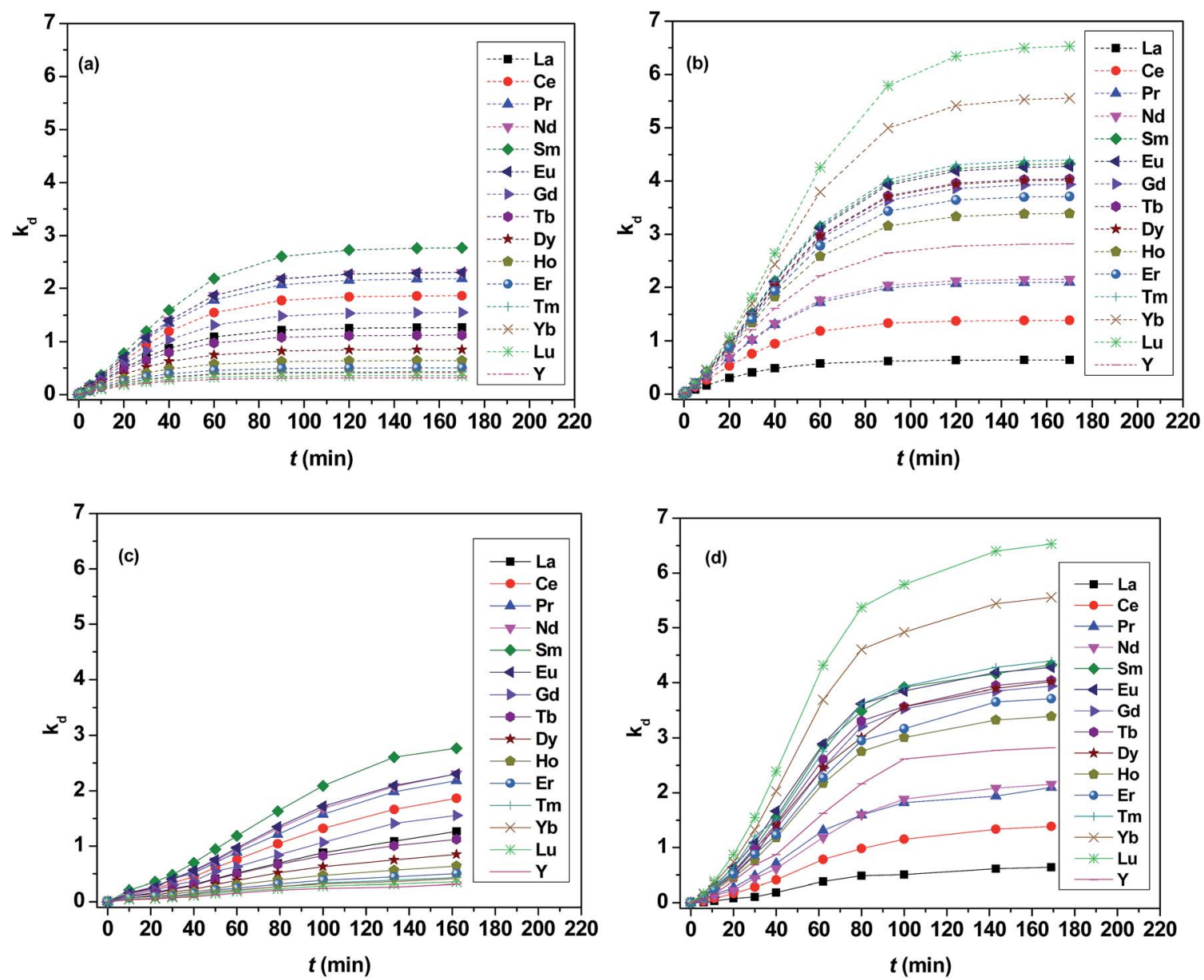

Fig. 3 Plots of distribution ratio versus time for the extraction of REEs. (a) and (b) are the predicted $k_{\mathrm{d}}$ value by theoretical calculations. (a) $V=$ $90 \mathrm{~cm}^{3}, A=12 \mathrm{~cm}^{2}, C_{\text {ini }}=0.002 \mathrm{~mol} \mathrm{~L}^{-1}, \delta=0.00179 \mathrm{~cm}, 300 \mathrm{rpm}, T=298 \mathrm{~K}$. Set $k_{\mathrm{d}}$ values of La-Lu plus $Y$ after extraction equilibrium equal to $1.27,1.86,2.18,2.30,2.77,2.30,1.55,1.12,0.849,0.641,0.505,0.430,0.415,0.358,0.315$, respectively. (b) $V=90 \mathrm{~cm}^{3}, A=12 \mathrm{~cm}^{2}, C_{\text {ini }}=$ $0.002 \mathrm{~mol} \mathrm{~L}^{-1}, \delta=0.00179 \mathrm{~cm}, 300 \mathrm{rpm}, T=298 \mathrm{~K}$. Set $k_{\mathrm{d}}$ values of La-Lu plus $Y$ after extraction equilibrium equal to 0.640, 1.39, 2.10, 2.15, 4.33, $4.28,3.94,4.04,4.02,3.39,3.71,4.40,5.56,6.53,2.82$, respectively. Organic phase: (c) $0.20 \mathrm{~mol} \mathrm{~L}^{-1} \mathrm{HPOAA}$ in $n$-heptane with saponification degree of $30 \%$. (d) $0.20 \mathrm{~mol} \mathrm{~L}^{-1}\left[\mathrm{~N}_{1888}\right]$ [POAA] in $n$-heptane without saponification. Aqueous phase: $\sum \mathrm{RECl}_{3}=0.030 \mathrm{~mol} \mathrm{~L}^{-1}\left(0.0020 \mathrm{~mol} \mathrm{~L}{ }^{-1}\right.$ each. $\mathrm{RE}=\mathrm{La}-\mathrm{Lu}$ plus $\mathrm{Y}$ except $\mathrm{Pm}), \mathrm{pH}=4.5 \mathrm{O}: \mathrm{A}=90 \mathrm{~mL}: 90 \mathrm{~mL}, A=12 \mathrm{~cm}^{2}, 300 \mathrm{rpm}, T=298 \mathrm{~K}$. 


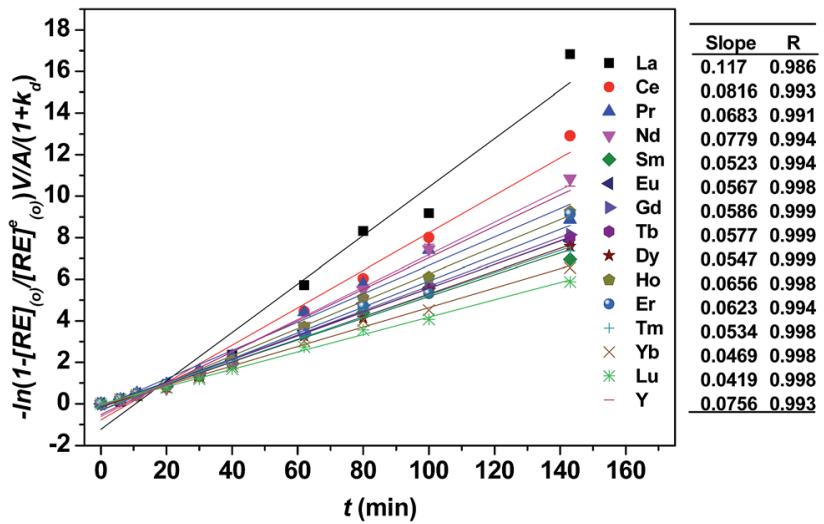

Fig. 4 Plots of $-\ln \left(1-[R E]_{(0)} /[R E]_{(0)}{ }^{e}\right) V / A /\left(1+k_{d}\right)$ vs. time in $\left[N_{1888}\right]$ [POAA] system. Organic phase: $0.20 \mathrm{~mol} \mathrm{~L}^{-1}\left[\mathrm{~N}_{1888}\right][\mathrm{POAA}]$ in $n$-heptane. Aqueous phase: $\sum \mathrm{RECl}_{3}=0.030 \mathrm{~mol} \mathrm{~L}^{-1}\left(0.0020 \mathrm{~mol} \mathrm{~L}^{-1}\right.$ each), $\mathrm{pH}=4.5, \mathrm{O}: \mathrm{A}=90 \mathrm{~mL}: 90 \mathrm{~mL}, A=12 \mathrm{~cm}^{2}, 300 \mathrm{rpm}, T=$ $298 \mathrm{~K}$.

The effect of the extraction rate on the stirring rate was adopted to identify the reaction regime of the current extraction system and the results are shown in Fig. 5. It is found that as the mixing speed increases, the extraction rates reached asymptotes from 100 to $300 \mathrm{rpm}$ but was nearly constant in the range of mixing speed exceeds $300 \mathrm{rpm}$. When the stirring speed exceeded $350 \mathrm{rpm}$, it was hard to maintain the quiescent interface. The independence of extraction rate from the stirring speed suggests that with increased stirring rate and average velocity $(U)$, the diffusion film $(\delta)$ became thinner and the diffusion resistance became smaller. Detailed discussion on the effect of stirring speed on $\delta$ and $U$ are in ESI (Fig. S1 $\dagger$ ). Beyond a distinct stirring rate, the diffusion resistance may be ignored and only the chemical reaction needs to be considered. Therefore, other kinetic experiments were measured at $300 \mathrm{rpm}$ to maintain the same hydrodynamic conditions in this work.

Table 2 The difference of the extraction rate between HPOAA system and $\left[\mathrm{N}_{1888}\right][\mathrm{POAA}]$ system

$\underline{k_{\mathrm{ao}}\left(\mathrm{mm} \mathrm{s}^{-1}\right)}$

\begin{tabular}{lllll}
$\mathrm{RE}^{3+}$ & (a) HPOAA & (b) $\left[\mathrm{N}_{1888}\right][$ POAA $]$ & HDEHP ref. 25 & $\Delta k_{\mathrm{ao}}=b / a$ \\
\hline $\mathrm{La}$ & $1.18 \times 10^{-2}$ & $1.25 \times 10^{-2}$ & $2.1 \times 10^{-1}$ & 1.05 \\
$\mathrm{Ce}$ & $1.70 \times 10^{-2}$ & $1.89 \times 10^{-2}$ & $1.6 \times 10^{-1}$ & 1.11 \\
$\mathrm{Pr}$ & $1.95 \times 10^{-2}$ & $2.39 \times 10^{-2}$ & $9.0 \times 10^{-2}$ & 1.22 \\
$\mathrm{Nd}$ & $1.98 \times 10^{-2}$ & $2.80 \times 10^{-2}$ & $3.7 \times 10^{-2}$ & 1.42 \\
$\mathrm{Sm}$ & $2.53 \times 10^{-2}$ & $3.77 \times 10^{-2}$ & $1.5 \times 10^{-2}$ & 1.49 \\
$\mathrm{Eu}$ & $2.06 \times 10^{-2}$ & $4.04 \times 10^{-2}$ & $1.2 \times 10^{-2}$ & 1.96 \\
$\mathrm{Gd}$ & $1.58 \times 10^{-2}$ & $4.13 \times 10^{-2}$ & $1.2 \times 10^{-2}$ & 2.61 \\
$\mathrm{~Tb}$ & $1.29 \times 10^{-2}$ & $3.89 \times 10^{-2}$ & $7.8 \times 10^{-3}$ & 3.02 \\
$\mathrm{Dy}$ & $1.02 \times 10^{-2}$ & $3.82 \times 10^{-2}$ & $7.9 \times 10^{-3}$ & 3.74 \\
$\mathrm{Ho}$ & $8.12 \times 10^{-3}$ & $3.71 \times 10^{-2}$ & $1.0 \times 10^{-2}$ & 4.57 \\
$\mathrm{Er}$ & $6.80 \times 10^{-3}$ & $3.86 \times 10^{-2}$ & $1.6 \times 10^{-2}$ & 5.67 \\
$\mathrm{Tm}$ & $6.38 \times 10^{-3}$ & $4.64 \times 10^{-2}$ & $3.4 \times 10^{-2}$ & 7.27 \\
$\mathrm{Yb}$ & $5.90 \times 10^{-3}$ & $4.34 \times 10^{-2}$ & $7.2 \times 10^{-2}$ & 7.37 \\
$\mathrm{Lu}$ & $5.56 \times 10^{-3}$ & $4.57 \times 10^{-2}$ & $9.9 \times 10^{-2}$ & 8.21 \\
$\mathrm{Y}$ & $4.21 \times 10^{-3}$ & $3.55 \times 10^{-2}$ & $1.0 \times 10^{-1}$ & 8.44
\end{tabular}

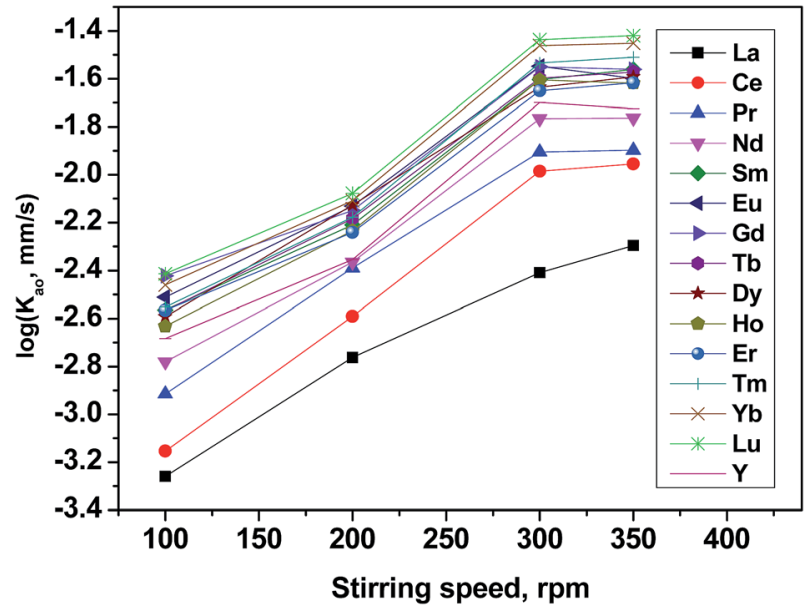

Fig. 5 Effect of stirring speed on extraction rate of mixed REEs. Organic phase: $0.20 \mathrm{~mol} \mathrm{~L}-1$ [N $\left.\mathrm{N}_{1888}\right][\mathrm{POAA}]$ in $n$-heptane. Aqueous phase: $\sum \mathrm{RECl}_{3}=0.030 \mathrm{~mol} \mathrm{~L}^{-1}\left(0.0020 \mathrm{~mol} \mathrm{~L}^{-1}\right.$ each), $\mathrm{pH}=4.5$, $\mathrm{O}: \mathrm{A}=90 \mathrm{~mL}: 90 \mathrm{~mL}, A=12 \mathrm{~cm}^{2}, T=298 \mathrm{~K}$.

Follow-up studies have shown that, the stirring speed did not affect the separation factors of REEs. The extraction order followed the same sequence in the $\left[\mathrm{N}_{1888}\right][\mathrm{POAA}]$ system at different stirring speed.

\subsection{Dependence of the extraction rate on temperature}

In the most general case, the extraction rate increases with the increasing temperature. Effect of temperature on extraction rate of mixed rare earths have been studied and results are shown in Fig. 6. Present study demonstrates increased sharply in the extraction of REEs with an increase at temperatures lower than $298 \mathrm{~K}$ and slowly at temperatures higher than $298 \mathrm{~K}$.

The activation energy, $E_{\mathrm{a}}$, was calculated according to the Arrhenius equation and the results are listed in Table 3.

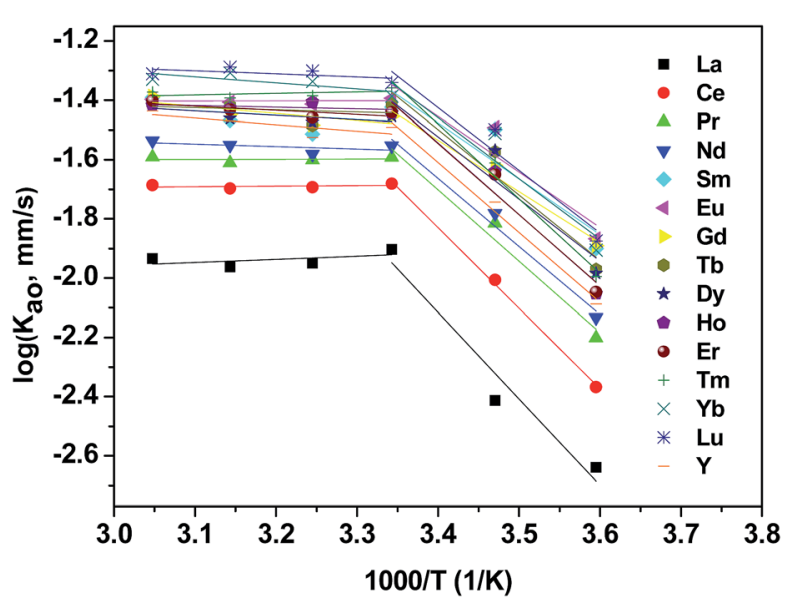

Fig. 6 Effect of temperature on extraction rate of mixed REEs. Organic phase: $0.20 \mathrm{~mol} \mathrm{~L}{ }^{-1}\left[\mathrm{~N}_{1888}\right][\mathrm{POAA}]$ in $n$-heptane. Aqueous phase: $\sum \mathrm{RECl}_{3}=0.030 \mathrm{~mol} \mathrm{~L}^{-1}$ (0.0020 mol L ${ }^{-1}$ each). $\mathrm{pH}=4.5 . \mathrm{O}: \mathrm{A}=$ $90 \mathrm{~mL}: 90 \mathrm{~mL}, A=12 \mathrm{~cm}^{2}, 300 \mathrm{rpm}$. 
Table 3 The activation energy calculated in the $\left[\mathrm{N}_{1888}\right][\mathrm{POAA}]$ system

\begin{tabular}{llc}
\hline & \multicolumn{2}{c}{$E_{\mathrm{a}}, \mathrm{kJ} \mathrm{mol}^{-1}$} \\
\cline { 2 - 3 } $\mathrm{RE}^{3+}$ & $<298 \mathrm{~K}$ & $>298 \mathrm{~K}$ \\
\hline $\mathrm{La}$ & 58.1 & 1.57 \\
$\mathrm{Ce}$ & 54.5 & 0.78 \\
$\mathrm{Pr}$ & 48.5 & 0.95 \\
$\mathrm{Nd}$ & 46.2 & 4.38 \\
$\mathrm{Sm}$ & 38.1 & 11.9 \\
$\mathrm{Eu}$ & 37.8 & 1.52 \\
$\mathrm{Gd}$ & 34.7 & 9.31 \\
$\mathrm{~Tb}$ & 44.5 & 7.11 \\
$\mathrm{Dy}$ & 42.3 & 6.33 \\
$\mathrm{Ho}$ & 48.6 & -1.07 \\
$\mathrm{Er}$ & 48.3 & 5.32 \\
$\mathrm{Tm}$ & 50.6 & 1.15 \\
$\mathrm{Yb}$ & 41.4 & 0.76 \\
$\mathrm{Lu}$ & 42.6 & -0.88 \\
$\mathrm{Y}$ & 47.4 & 8.59
\end{tabular}

$$
\log k_{\mathrm{ao}}=-\frac{E_{\mathrm{a}}}{2.303 R T}+C
$$

where $C$ is known as the pre-exponential factor.

It is reported that a process was characterized as diffusion controlled when $E_{\mathrm{a}}$ was $<20 \mathrm{~kJ} \mathrm{~mol}^{-1}$ or as chemical reaction controlled when $E_{\mathrm{a}}$ was $>42 \mathrm{~kJ} \mathrm{~mol}^{-1}$. ${ }^{40}$ Correspondingly, it suggests that a chemical reaction controlled regime when temperatures were lower than $298 \mathrm{~K}$ and a diffusion controlled regime when temperatures exceeded $298 \mathrm{~K}$.

The temperature does affects the separation factors of REEs. As shown in Table 4, the separation factor of heavy REEs of Tm, $\mathrm{Yb}$ and $\mathrm{Lu}$ in the $\left[\mathrm{N}_{1888}\right][\mathrm{POAA}]$ system increased $16.2 \%, 29.5 \%$ and $34.6 \%$ when the temperature increased from $278 \mathrm{~K}$ to $328 \mathrm{~K}$, respectively. When it comes to light REEs, there are different rate decrease of the separation factor of $\mathrm{La}, \mathrm{Ce}, \mathrm{Pr}, \mathrm{Nd}, \mathrm{Sm}, \mathrm{Eu}$, $\mathrm{Gd}$ and Tb. Similar results were reported that when the temperature increased from $278 \mathrm{~K}$ to $333 \mathrm{~K}$, the separation factor of $\mathrm{Tm} / \mathrm{Yb}$ and $\mathrm{Yb} / \mathrm{Lu}$ in the P507 and C272 extraction system increased form 1.13 and 1.18 to 2.31 and 1.68 ,

Table 4 The separation factor calculated at $278 \mathrm{~K}, 288 \mathrm{~K}, 298 \mathrm{~K}, 308 \mathrm{~K}$, $318 \mathrm{~K}$ and $328 \mathrm{~K}$ in the $\left[\mathrm{N}_{1888}\right][\mathrm{POAA}]$ system

\begin{tabular}{lllllll}
\hline$\beta_{\mathrm{Ln} / \mathrm{Y}}$ & $278 \mathrm{~K}$ & $288 \mathrm{~K}$ & $298 \mathrm{~K}$ & $308 \mathrm{~K}$ & $318 \mathrm{~K}$ & $328 \mathrm{~K}$ \\
\hline $\mathrm{La}$ & 0.29 & 0.28 & 0.23 & 0.23 & 0.21 & 0.21 \\
$\mathrm{Ce}$ & 0.53 & 0.61 & 0.49 & 0.54 & 0.48 & 0.47 \\
$\mathrm{Pr}$ & 0.78 & 0.90 & 0.74 & 0.71 & 0.77 & 0.74 \\
$\mathrm{Nd}$ & 0.90 & 0.94 & 0.76 & 0.83 & 0.83 & 0.78 \\
$\mathrm{Sm}$ & 1.82 & 1.87 & 1.53 & 1.61 & 1.54 & 1.39 \\
$\mathrm{Eu}$ & 1.95 & 1.99 & 1.52 & 1.67 & 1.56 & 1.37 \\
$\mathrm{Gd}$ & 1.49 & 1.64 & 1.40 & 1.32 & 1.23 & 1.14 \\
$\mathrm{~Tb}$ & 1.66 & 1.71 & 1.43 & 1.48 & 1.53 & 1.43 \\
$\mathrm{Dy}$ & 1.64 & 1.61 & 1.43 & 1.65 & 1.58 & 1.61 \\
$\mathrm{Ho}$ & 1.37 & 1.41 & 1.20 & 1.38 & 1.49 & 1.39 \\
$\mathrm{Er}$ & 1.45 & 1.41 & 1.32 & 1.49 & 1.55 & 1.47 \\
$\mathrm{Tm}$ & 1.66 & 1.59 & 1.55 & 1.82 & 1.96 & 1.93 \\
$\mathrm{Yb}$ & 2.12 & 2.12 & 2.09 & 2.43 & 2.68 & 2.74 \\
$\mathrm{Lu}$ & 2.28 & 2.33 & 2.32 & 2.67 & 2.87 & 3.07
\end{tabular}

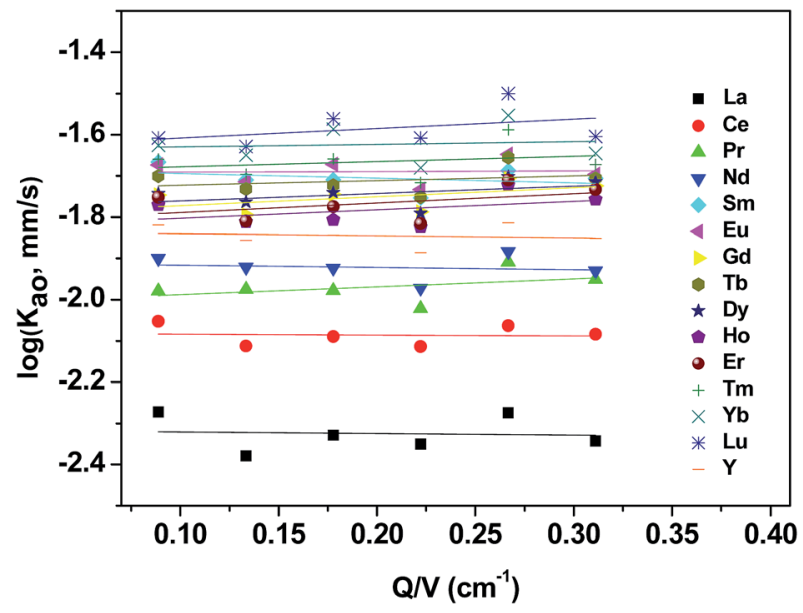

Fig. 7 Effect of specific interfacial area on extraction rate of mixed REEs. Organic phase: $0.20 \mathrm{~mol} \mathrm{~L}{ }^{-1}\left[\mathrm{~N}_{1888}\right][\mathrm{POAA}]$ in $n$-heptane. Aqueous phase: $\sum \mathrm{RECl}_{3}=0.030 \mathrm{~mol} \mathrm{~L}^{-1}\left(0.0020 \mathrm{~mol} \mathrm{~L}^{-1}\right.$ each), $\mathrm{pH}=$ $4.5, \mathrm{O}: \mathrm{A}=90 \mathrm{~mL}: 90 \mathrm{~mL}, A=8-28 \mathrm{~cm}^{2}, 300 \mathrm{rpm}, T=298 \mathrm{~K}$.

respectively. ${ }^{41}$ In combination with Fig. 6, it might be explained that although the absolute extraction rates of all REEs increase with the increasing temperature, the absolute extraction rates of heavy REEs increases higher than that of light REEs which result in the growing gaps of separation factors between heavy REEs and light REEs.

\subsection{Dependence of the extraction rate on specific interfacial area}

To examine the dependence of the extraction rate, mass transfer rates were obtained as function of the specific interfacial area $(A / V)$ at a constant stirring speed (300 rpm). As shown in Fig. 7, the extraction rate was independent of the specific interfacial area, which indicated that reactions occurring in the bulk of the phases rather than rate determining.

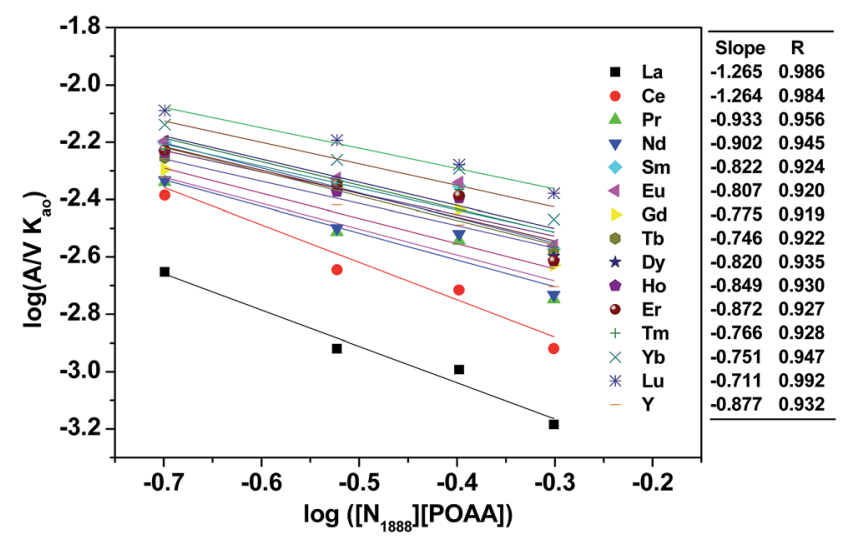

Fig. 8 Effect of $\left[\mathrm{N}_{1888}\right][\mathrm{POAA}]$ concentration on extraction rate of mixed REEs. Organic phase: $0.20-0.50 \mathrm{~mol} \mathrm{~L}^{-1}\left[\mathrm{~N}_{1888}\right]$ [POAA] in $n$-heptane. Aqueous phase: $\sum \mathrm{RECl}_{3}=0.030 \mathrm{~mol} \mathrm{~L}^{-1}\left(0.0020 \mathrm{~mol} \mathrm{~L}^{-1}\right.$ each), $\mathrm{pH}=4.5, \mathrm{O}: \mathrm{A}=90 \mathrm{~mL}: 90 \mathrm{~mL}, A=12 \mathrm{~cm}^{2}, 300 \mathrm{rpm}, T=$ $298 \mathrm{~K}$. 
Table 5 The forward extraction constant of REEs

\begin{tabular}{|c|c|c|c|c|c|c|c|c|c|c|c|c|c|c|c|}
\hline $\mathrm{La}$ & $\mathrm{Ce}$ & $\operatorname{Pr}$ & $\mathrm{Nd}$ & $\mathrm{Sm}$ & $\mathrm{Eu}$ & $\mathrm{Gd}$ & $\mathrm{Tb}$ & Dy & Ho & Er & $\mathrm{Tm}$ & $\mathrm{Yb}$ & $\mathrm{Lu}$ & $\mathrm{Y}$ & Average \\
\hline 0.054 & 0.054 & 0.117 & 0.125 & 0.151 & 0.156 & 0.168 & 0.179 & 0.151 & 0.142 & 0.134 & 0.171 & 0.178 & 0.194 & 0.133 & 0.141 \\
\hline
\end{tabular}

\subsection{Extraction rate equation of REEs}

Based on the mechanism of neutral extraction combined with ion association in the bifunctional ionic liquid system, ${ }^{\mathbf{1 7}}$ the extraction equation of REEs with $\left[\mathrm{N}_{1888}\right][\mathrm{POAA}]$ can be presented as follows:

$$
\mathrm{RECl}_{3}+\left[\mathrm{N}_{1888}\right][\mathrm{POAA}]_{(\mathrm{o})} \rightleftarrows\left[\mathrm{N}_{1888}\right] \mathrm{Cl} \cdot \mathrm{REPOAACl}{ }_{2}
$$

Accordingly, the extraction rate equation of REEs can be proposed as:

$$
R_{\mathrm{f}}=-\frac{\mathrm{d}[\mathrm{RE}]_{(\mathrm{o})}}{\mathrm{d} t}=k_{\mathrm{f}}\left[\mathrm{RECl}_{3}\right]\left(\left[\mathrm{N}_{1888}\right][\mathrm{POAA}]\right)
$$

where, $k_{\mathrm{f}}$ is the forward extraction constant.

To simplify the calculation model, the reverse extraction rate can be ignored when the concentration of extractant in the organic phase is much higher than the concentration of metal ions in the aqueous phase. Combining eqn (2) and (10), one can write the following equation:

$$
\frac{A}{V} k_{\mathrm{ao}}=k_{\mathrm{f}}\left(\left[\mathrm{N}_{1888}\right][\mathrm{POAA}]\right)
$$

By investigating the effect of $\left[\mathrm{N}_{1888}\right][\mathrm{POAA}]$ concentration on extraction rate of mixed REEs (Fig. 8), $k_{\mathrm{f}}$ of REEs were obtained and the results are shown in Table 5 . Therefore, the average extraction rate equation of REEs can be expressed as: $-\mathrm{d}[\mathrm{RE}]_{(\mathrm{o})} /$ $\mathrm{d} t=0.141\left[\mathrm{RECl}_{3}\right]\left(\left[\mathrm{N}_{1888}\right][\mathrm{POAA}]\right)$.

\section{Conclusions}

The extraction kinetics of mixed REEs with bifunctional ionic liquid $\left[\mathrm{N}_{1888}\right][\mathrm{POAA}]$ using a constant interfacial area cell were reported and characterized. The experimental results show that practical kinetic values obtained from kinetic experiments fit the data predicted by theoretical calculations very well. The relative errors of experimental values and theoretical values are less than $43 \%$ and $25 \%$ in the HPOAA and $\left[\mathrm{N}_{1888}\right][\mathrm{POAA}]$ extraction system after 80 minutes, respectively. Effect of stirring speed, temperature specific interfacial area and extractant concentration on the extraction rate of REEs were studied. $300 \mathrm{rpm}$ was suggested to ensure the extraction regimes were chemical reaction-controlled rather than diffusion-controlled when the temperatures were lower than $298 \mathrm{~K}$. The extraction rate was independent of the specific interfacial area, which indicated that reactions occurring in the bulk of the phases. The average extraction rate equation of REEs have also been obtained using a constant interfacial area cell as: $-\mathrm{d}[\mathrm{RE}]_{(\mathrm{o})} / \mathrm{d} t=$ $0.141\left[\mathrm{RECl}_{3}\right]\left(\left[\mathrm{N}_{1888}\right][\right.$ POAA $\left.]\right)$. Kinetic data obtained above will be used to recognize the thermodynamic mechanism and optimize extraction processes.

\section{Conflicts of interest}

There are no conflicts to declare.

\section{Acknowledgements}

This work was supported by National Natural Science Foundation of China (21571179), Science and Technology Major Projects of Fujian Province (2015HZ0001-3), Natural Science Foundation of Fujian Province (2016J0102) and Science and Technology Service Network Initiative.

\section{Notes and references}

1 A. Rout, S. Wellens and K. Binnemans, RSC Adv., 2014, 4, 5753-5758.

2 Q. Su, Presented in part at the Proceedings of the 9th China rare earth Entrepreneur Association Conference, 2008.

3 D. Q. Li, Prog. Chem., 1995, 7, 209-213.

4 C. H. Yan, J. T. Jia, C. S. Liao, S. Wu and G. X. Xu, Tsinghua Sci. Technol., 2006, 11, 241-247.

5 J. C. Xiao, Presented in part at the Proceedings of the Ninth National Symposium on Inorganic Chemistry of China Chemical Society, Nanchang, China, 2015-07-25, 2015.

6 X. Q. Sun, B. Peng, J. Chen, D. Q. Li and F. Luo, Talanta, 2008, 74, 1071-1074.

7 J. G. Huddleston, A. E. Visser, W. M. Reichert, H. D. Willauer, G. A. Broker and R. D. Rogers, Green Chem., 2001, 3, 156-164.

8 X. Q. Sun and K. E. Waters, ACS Sustainable Chem. Eng., 2014, 2, 2758-2764.

9 A. Rout, K. A. Venkatesan, T. G. Srinivasan and P. V. Rao, Sep. Purif. Technol., 2012, 95, 26-31.

10 X. Q. Sun, Y. Ji, L. Zhang, J. Chen and D. Q. Li, J. Hazard. Mater., 2010, 182, 447-452.

11 Y. H. Chen, H. Y. Wang, Y. C. Pei, J. Ren and J. J. Wang, ACS Sustainable Chem. Eng., 2015, 3, 3167-3174.

12 W. Wang, H. L. Yang, H. M. Cui, D. L. Zhang, Y. Liu and J. Chen, Ind. Eng. Chem. Res., 2011, 50, 7534-7541.

13 H. L. Yang, J. Chen, W. Wang, H. M. Cui, W. G. Liu and Y. Liu, Sci. China: Chem., 2016, 59, 532-537.

14 W. Z. Ye, in Advances in Rare Earth New Materials and New Processes, Science Press, Beijing, 1998, pp. 3-10.

15 Y. G. Wang, S. T. Yue, D. Q. Li, M. J. Jin and C. Z. Li, Solvent Extr. Ion Exch., 2002, 20, 701-716.

16 Y. L. Wang, H. Y. Zhou, Y. B. Wang, F. J. Li and X. Q. Sun, Sep. Purif. Technol., 2017, 184, 280-287.

17 Y. L. Wang, C. Huang, F. J. Li, Y. M. Dong, Z. Y. Zhao and X. Q. Sun, Sep. Purif. Technol., 2016, 162, 106-113.

18 M. A. Jeannot and F. F. Cantwell, Anal. Chem., 1997, 69, 235239. 
19 N. S. Awwad, Chem. Eng. Process., 2004, 43, 1503-1509.

20 F. Kubota, M. Goto and F. Nakashio, Sep. Sci. Technol., 1995, 30, 777-792.

21 S. H. Lin and R. S. Juang, Ind. Eng. Chem. Res., 2002, 41, 853861.

22 C. Ungureanu, L. Marchal, A. A. Chirvase and A. Foucault, Bioresour. Technol., 2013, 132, 406-409.

23 J. J. Liu, Y. L. Wang and D. Q. Li, J. Chem. Technol. Biotechnol., 2007, 82, 949-955.

24 D. Datta and S. Kumar, Ind. Eng. Chem. Res., 2013, 52, 1468014686.

25 K. P. Nichols, R. R. Pompano, L. Li, A. V. Gelis and R. F. Ismagilov, J. Am. Chem. Soc., 2011, 133, 15721-15729.

26 S. H. Yin, S. W. Li, J. H. Peng and L. B. Zhang, RSC Adv., 2015, 5, 48659-48664.

27 C. Q. Chen and T. Zhu, Solvent Extr. Ion Exch., 1994, 12, 1013-1032.

28 J. Lu, G. X. Ma, D. Q. Li and M. S. Ni, Chin. J. Appl. Chem., 1998, 15, 43-46.

29 Y. L. Wang, Y. L. Li, D. Q. Li and W. P. Liao, Hydrometallurgy, 2013, 140, 66-70.
30 S. T. Yue, W. P. Liao, D. Q. Li and Q. Su, Chin. J. Chem., 2002, 20, 545-549.

31 Y. G. Wang, S. T. Yue and D. Q. Li, Solvent Extr. Ion Exch., 2002, 20, 345-358.

32 W. P. Liao, G. H. Yu, S. T. Yue and D. Q. Li, Talanta, 2002, 56, 613-618.

33 B. Wei, Master of Science, University of Jinan, 2005.

34 H. L. Yang, J. Chen, W. Wang, H. M. Cui, D. L. Zhang and Y. Liu, Chin. J. Chem. Eng., 2014, 22, 1174-1177.

35 L. Chen, Doctor of Natural Science, The University of Chinese Academy of Sciences, 2016.

36 F. KneißI, A. Aeist and W. Nitsch, Solvent Extr. Ion Exch., 1999, 17, 475-493.

37 P. R. Danesi, R. Chiarizia and C. F. Coleman, CRC Crit. Rev. Anal. Chem., 1980, 10, 1-126.

38 Z. Zheng, J. Lu, D. Q. Li and G. X. Ma, Chem. Eng. Sci., 1998, 53, 2327-2333.

39 H. L. Yang, W. Wang, H. M. Cui, D. L. Zhang, Y. Liu and J. Chen, J. Chem. Technol. Biotechnol., 2012, 87, 198-205.

40 J. F. Yu and C. Ji, Chem. Res. Chin. Univ., 1992, 13, 224-226.

41 W. H. Yang, S. H. Zhang, S. Wu, H. P. Li and Q. Z. Fan, China Pat., CN201110408624.3, 09-12-2011. 